\title{
Occupational Allergic Rhinitis: What Do We Know?
}

\section{Dilşad Mungan, MD}

\author{
Address \\ Department of Pulmonary Diseases, Division of Allergy and Immunology, School of \\ Medicine, Ankara University, Ankara, Turkey \\ Email:mungan@medicine.ankara.edu.tr
}

Published online: 16 December 2014

(C) Springer International Publishing AG 2014

This article is part of the Topical Collection on Allergic Rhinitis

Keywords Occupational rhinitis - Occupational asthma - Work related rhinitis - Occupational allergy $\cdot$ Rhinitis

\section{Opinion statement}

- The main objectives of the management of occupational rhinitis are, elimination of symptoms and prevention of development of asthma.

- Management strategies include, environmental interventions (cessation or reducing the exposure to the causal agent) and appropriate pharmacologic treatment.

- Drug therapy does not differ from non-occupational rhinitis.

- Given the increased risk for occupational asthma in patients with occupational rhinitis, the most effective approach is complete avoidance of exposure to the offending agent. However, if complete cessation of exposure leads to adverse socio-economic measures, reduction in contact with the agent in combination with drug therapy can be considered. - Allergen immunotherapy (AIT) has been used for a few sensitizers in occupational allergic diseases. The use of AIT is very limited due to inadequate standardization of occupational allergens. Effective treatment of patients with occupational allergy by the use of AIT may allow workers to continue their work when exposure can not be avoided. The new technologies are expected to improve the quality and efficacy of specific immunotherapy in patients with occupational allergy in the future.

\section{Introduction}

Occupational rhinitis has gained increased attention as an occupational disease in the recent years. According to the accumulating evidence it is $2-4$ times frequent than occupational asthma. It is an important clinical entity because occupational rhinitis constitutes a higher risk for the development of occupational asthma [1]. The first step in the diagnosis is to think about the possibility of an occupational etiology in a patient describing upper airway symptoms. The diagnostic algorhtym includes a careful history and nasal examination, immunological tests if possible, nasal provocation tests in the laboratory and workplace assessment [2 (See Table 1.)]. A definite diagnosis is an essential step in the management of 
the disease as decision for avoidance of exposure is based on occupational causality of rhinitis.

Management strategies in patients with occupational rhinitis include elimination or reduction of exposure to the casual agent in the workplace and drug treatment. Pharmacologic treatment is not different from that of non-occupational rhinitis. Allergen immunotherapy
(AIT) has been reported to be effective in several studies with few agents, however it is a promising treatment in

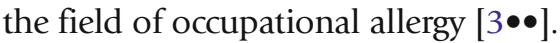

This review summarizes the diagnostic approach to a patient with occupational upper airway symptoms and updates the existing knowledge on the management of occupational rhinitis based on the current literature.

\section{Definition and classification}

Allergic occupational rhinitis

Nonallergic occupational rhinitis

Occupational rhinitis (OR) is an inflammatory disease of the nose, characterized by intermittent or persistent symptoms due to causes in the work environment. Work exacerbated rhinitis is pre-existing or concurrent rhinitis exacerbated by workplace exposures [4]. The term work-related rhinitis covers the two conditions.

Workers can be exposed to various agents which induce or trigger upper airway symptoms in the workplace. These reactions can occur through immunological and non immunological mechanisms. Occupational rhinitis can be classified according to the etiopathogenic mechanisms as; allergic and nonallergic OR [4-7] (Fig. 1).

\begin{tabular}{|c|c|}
\hline & 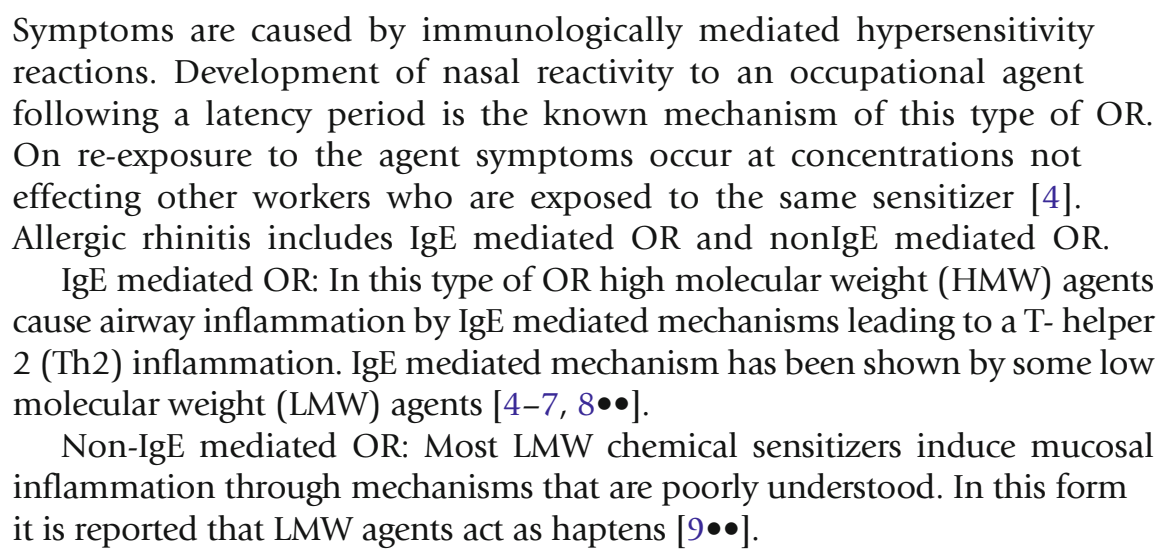 \\
\hline
\end{tabular}

Rhinitis results from exposure to agents considered to be irritants in the absence of sensitization. In this type of occupational rhinitis transient or persistent symptoms begin after one or more high level exposure to an irritant agent. This entity is named as "irritant induced OR" which usually occurs without a latency period. It is quite similar to the "reactive airway dysfunction syndrome" (RADS) described for asthma, so it is proposed that irritant induced rhinitis should be termed as "reactive upper airway dysfunction syndrome" (RUDS) [10]. It is reported that low concentrations of irritating chemicals at workplace could induce asthma $[9 \bullet \bullet]$. This may also refer to symptoms of rhinitis for subjects repeatedly exposed to irritants (vapors, fumes, smokes, dusts) without exposure to high concentrations. Another clinical entity is "corrosive rhinitis" which is 
Table 1. Management of occupational rhinitis

1. Environmental interventions

2. Pharmacologic treatment

3. Immunological treatments

4. Surveillance programs
Complete avoidance

Work change

Reduction of exposure

Reducing the duration and intensity of exposure No difference from nonoccupational rhinitis

Specific immunotherapy

Few allergens (Laboratory animals, flour, latex)

Omalizumab

Few reports for occupational asthma

Investigation of possible asthma

associated with ulcerations of the mucosa and perforation of nasal septum due to exposure to high concentrations irritating chemicals [11].

Work exacerbated rhinitis: In this condition rhinitis symptoms are triggered by various agents at workplace. Clinical findings of work exacerbated rhinitis are similar to those of occupational rhinitis. It is suggested that work exacerbated asthma should be considered in any patient with asthma that is getting worse at work or who has work-related symptoms [12, 13]. The same approach can be proposed for the upper airway symptoms triggered in the work place. A careful history and exclusion of exposure to a specific agent in the workplace is needed for the diagnosis of work exacerbated rhinitis [11].

\section{Epidemiology}

Although the prevalence of occupational asthma has been widely studied, epidemiology of occupational rhinitis has been investigated less, probably because it is not considered to be a serious disease [14]. In the general population rhinitis is 3 times more prevalent than asthma [15]. According to the

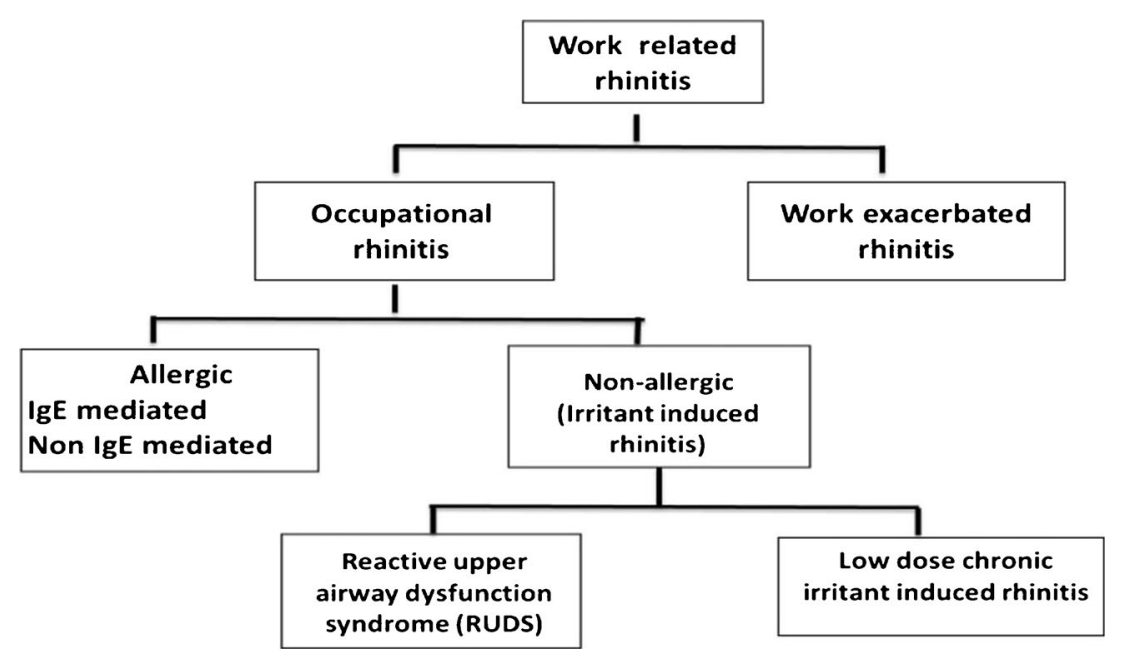

Fig. 1. Classification of occupational rhinitis. 
results of cross sectional studies conducted in various working populations, occupational rhinitis occurs 2-4 times more frequently than occupational astma $[4-7,8 \bullet \bullet, 9 \bullet \bullet, 10-14]$.

It is known that up to $90 \%$ of individuals with asthma suffer from rhinitis and $40 \%$ of patients with rhinitis have asthma symptoms [16]. Available data suggest that nasal symptoms are present in up to $90 \%$ of subjects with occupational asthma [14] and occupational rhinitis may be a marker of developing occupational asthma. Few studies have evaluated the relationship between the onset of occupational asthma and occupational rhinitis in subjects who have the both conditions. Cullinan et al. reported that the median period for the beginning of nasal symptoms were 12 months, where as it was 18 months for pulmonary symptoms in workers exposed to rats [17]. In subjects working with laboratory animals rhinitis symptoms occured in $45 \%$ of workers before asthma [14]. Malo et al. showed nasal symptoms appeared before the onset of occupational asthma in $58 \%$ of the exposed workers with HMW agents, but only in $25 \%$ with LMW agents [18]. Recently in a large series of occupational asthma, it was reported that occupational asthma and occupational rhinitis coexist significantly more frequently when HMW agents are involved. This study confirmed that rhinitis symptoms occured before asthma symptoms significantly more frequently for HMW agents than for LMW agents, suggesting different pathophysiological mechanisms [19].

The aetiological agents of occupational rhinitis, like those of occupational asthma are HMW and LMW compounds [ $9 \bullet \bullet$ ]. Occupational rhinitis may also develop following exposure to irritants [14]. Among HMW agents, laboratory animal allergens, insects and mites, grain dust, flour, latex, some other plant allergens such as tobacco leaf, gren coffee and castor beans, biological enzymes and fish and seafood protein have been reported as aetiological agents in occupational rhinitis $[4-7,8 \bullet \bullet, 9 \bullet \bullet, 10-13]$. LMW compounds such as diisocyanates, anhydrides, wood dust, metals, drugs and some chemicals were found to induce nasal symptoms in exposed workers $[2,3 \bullet \bullet, 4-7$, $8 \bullet \bullet, 9 \bullet \bullet, 10-14]$. In a recent study we demonstrated that $25 \%$ of pet shop workers had upper airway symptoms at workplace [20].

Main determinants of occupational sensitization appear to be atopy, exposure and smoking status. Atopy has been associated with an increased risk of sensitization to HMW agents and and with occupational rhinitis caused by these compounds [4]. However there are inconsistent results regarding the relation between atopy and occupational rhinitis. Several papers have studied the relationship between occupational exposure and occupational rhinitis or sensitization [21-24]. There was a relationship between exposure and sensitization to HMW agents depending on the duration and intensity of exposure [21-24]. The relationship between smoking and occupational sensitization remains controversial [4].

\section{Diagnosis}

The diagnosis of occupational rhinitis includes both demonstrating the presence of rhinitis and its relation to the workplace. The steps involved in investigation are the clinical history, nasal examination, immunological tests and specific nasal provocation test [1]. In addition the possibility of co-existing 
asthma should be kept in mind and investigated by the use of questionnaires and pulmonary function tests $[25,26]$.

A detailed medical history is essential to establish the timing of nasal symptoms in relation to occupational exposure. Symptoms of runny nose, nasal obstruction, sneezing, itch and nose bleeds linked to specific exposures at work are suggestive for occupational rhinitis $[4-7,8 \bullet \bullet]$. Nasal symptoms can often be associated with conjunctival complaints [4]. Additional complaints of facial pressure, postnasal drip and smell reduction are suggestive for progression toward rhinosinusitis $[8 \bullet \bullet]$. However given the high frequency of upper airway symptoms in the general population, objective tests are essential to confirm a causal link between the suspected workplace agent and symptoms [2].

Nasal examination includes anterior rhinoscopy and nasal endoscopy, however the main value of these assessments is to rule out other nasal pathologies. Assessment of nasal patency, nasal inflammation and nonspecific nasal hyperreactivity are among the recommended tests for the diagnosis of occupational rhinitis [4]. They are useful when performed following nasal allergen challenge [27].

IgE mediated sensitization can be demonstrated by means of skin prick tests or serum specific IgE when the work related symptoms are linked to a HMW agent $[8 \bullet \bullet$. However LMW compounds do not necessarily lead symptoms through an IgE mediated mechanism. Positive test results may occur in exposed subjects [28]. If appropriate allergens are used and the tests are negative the diagnosis of occupational rhinitis can be excluded.

A causal relationship between exposure to a specific occupational agent and rhinitis syptoms can be established by specific nasal provocation testing (NPT) with the suspected agent. These tests are still accepted as the gold standard for confirming the diagnosis of occupational rhinitis [29, 30]. NPT can be performed in the laboratory by mimicking the conditions at the workplace or at work under natural conditions. The response may be assessed using the symptoms or by assessment of nasal inflammation, investigation of nasal lavage or evaluation of nasal congestion with the use of rhinomanometry, acoustic rhinometry and peak nasal inspiratory flow [31, 32].

The European Academy of Allergy and Clinical Immunology Task Force on occupational rhinitis reported a consensus diagnostic algorithm for occupational rhinitis [4]:

1. Clinical and medical history and nasal examination

2. Immunological evaluation

Suggestive clinical history plus positive immunological test can be considered as probable occupational rhinitis

3. NPT

If NPT is positive, definite diagnosis of occupational asthma can be established.

If NPT is negative in the presence of suggestive history or NPT is not feasible, workplace assessment should be performed.

\section{Management}

The management of occupational rhinitis should have two objectives; reducing rhinitis symptoms and preventing the development of 
occupational asthma $[2,3 \bullet \bullet, 4-8 \bullet \bullet, 9 \bullet \bullet]$. Management strategies include elimination or reduction of exposure to the offending agent combined with pharmacologic treatment of rhinitis $[1,2,3 \bullet \bullet, 4]$.

\section{Environmental avoidance measures}

Avoidance of exposure is a very important part of treatment, however complete prevention of exposure is associated with socio-economic consequences and the workers are reluctant for work changes because they are under the risk of losing their job. Reduction of exposure is a reasonable alternative. Reduced exposure can be achieved by improving ventilation systems, wearing appropriate protective clothing and masks if possible [33•].

Because it is clear that patients suffering from occupational upper airway disease are at higher risk of developing occupational asthma, it may be rea-

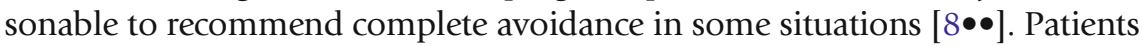
with nonspecific bronchial hyperreactivity are ideal candidates for complete avoidance as these subjects have a higher risk of developing asthma. Secondly subjects whose workplace have suitable conditions for relocation can be employed at another part of the company where unexposure is possible [4]. A recent Cochrane review compared the complete avoidance of exposure to the causal agent with reduction of exposure in occupational asthma. Complete removal resulted with significant clinical improvement where as reduction of exposure was less effective on asthma control. However there was a lower risk of unemployement in reduction group [34]. Another systematic review reported similar results [35]. These findings in occupational asthma can be reflected to occupational rhinitis.

When adequate reduction in exposure is impossible or insufficient, occupational rhinitis should be treated according to the guidelines for nonoccupational rhinitis. In case of HMW agents, Allergic Rhinitis and Its Impact on Asthma (ARIA) guidelines for the treatment of allergic rhinitis are indicated with the use of topical steroids and/or antihistamines. A stepwise medical treatment is proposed in the ARIA guidelines [15]. In patients with mild intermittent disease, oral or intranasal antihistaminics are recommended. In moderate-severe intermittent and mild persistent disease, oral or intranasal antihistaminics and/or decongestants or intranasal corticosteroids or leukotriene antagonists are suggested. In cases with moderatesevere persistent disease the first line recommendation is intranasal corticosteroids. However it should be kept in mind that medications should not be considered a suitable alternative to elimination or reduction in the workplace exposure to the sensitizing agent.

Because it is expected that patients with occupational rhinitis are under the risk of developing occupational asthma, a close follow-up for asthma symptoms is necessary. 
only for a few sensitizers. Most data refer to latex, flour, laboratory animals and

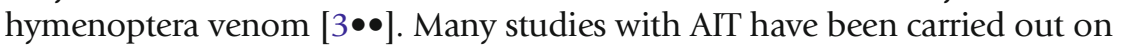
latex allergy, showing overall favorable results [36]. Recently Nettis et al. published a review on clinical trials of AIT in latex allergy. Eleven trials were analysed. Two of the three SCIT studies showed an improvement in clinical symptoms but the incidence of side effects were high. Five out of six randomised placebo controlled SLIT trials reported clinical improvement with a better safety profile [37]. On the other hand, few case reports have documented the efficacy of immunotherapy in baker's asthma. A retrospective study in which 41 allergic bakers received SCIT with wheat flour extract for 4 or more years and they were able to continue their work for several following the cessation of AIT [38]. Many efforts have been made to reduce exposure to laboratory animal allergy in the workplace, however laboratory animal allergy remains an occupational health problem. Only few data are available on the use of AIT in occupational rhinitis with laboratory animal allergens. A biologist who worked with rats had severe rhino-conjunctivitis and asthma and was sensitized to rat epithelium, as a work change was impossible for her, she received 18 months immunotherapy with rat epithelium extract. Immunotherapy resulted with complete symptom relief and the patient was able to continue work [39]. Recently subcutaneous immunotherapy with cow dander was reported to decrease rhinitis symptoms in a cow breeder mono-sensitized to cow dander [40].

However, due to lack of standardized allergens for most occupational agents the use of AIT is limited. The new technologies, including component-resolved diagnosis and recombinant allergens, are expected to improve the quality and efficacy of AIT in the future. Molecular diagnosis has been used in the diagnosis of occupational allergy to

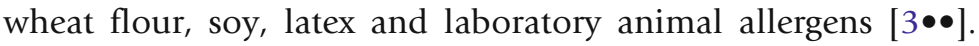

The use of omalizumab may represent a suitable therapeutic choice in very selected cases of occupational allergy. Studies demonstrated that omalizumab provided clinical benefit in patients with seasonal allergic rhinitis [41]. In patients with asthma and rhinitis, omalizumab improved nasal and bronchial symptoms and reduced unscheduled visits due to asthma [42]. Cost-effectiveness of anti-IgE has been appreciated for its indication in severe asthma but not for rhinitis [15]. This treatment had been shown to be effective in occupational latex allergy [43], in single case reports of bakers with asthma enabling them to continue work [44]. A recent study demonstrated that the treatment with omalizumab is effective in improving asthma control in 10 patients with occupational asthma who remained exposed to the causal agent $[45 \bullet]$.

\section{Prevention}

It is known that rhinitis caused by occupational agents will often develop into occupational asthma. This makes the cessation of allergen exposure a very important intervention in occupational allergic rhinitis. Primary and secondary preventive measures can reduce the incidence of occupational rhinitis, thus the development of occupational asthma. 
Primary prevention targets to prevent development of sensitization to the agents in the workplace. The measures include methods that workers are not exposed to agents that cause occupational rhinitis. One way is to replace the sensitizing agent with nonsensitizing compounds. An example for this method is the use of nonlatex gloves instead of gloves made of natural latex. Unfortunately many sensitizers cannot be replaced with nonsensitizing agents. For examle flour has to be used in bakeries and cannot be replaced. For this reason methods for reducing exposure have been suggested, these are, containment, improved ventilation, the use of personal protective equipment and education of the workers $[9 \bullet \bullet$. Examples of effective prevention of exposure have been reported for several causative agents such as, enzyme detergent production, platinium refining workers, laboratory workers, and health care workers using latex gloves [4]. Several studies demonstrated that, encapsulation of enzymes in the detergent industry, reduced exposure to laboratory animals and education of bakers were the methods used in primary prevention of occupational asthma [46-48]. In the case of diisocyanates, measures include use of polymeric instead of monomeric diisocyanates, formulation of less volatile compounds and measuring workplace concentrations.

Secondary prevention includes determination of workers at risk of developing occupational allergy in the early years of exposure by the use of surveillance programmes. Medical surveillance programmes should contain periodic administration of questionnaires, detection of sensitization by skin prick tests or serum specific IgE measurements, early recognization of symptomatic workers and referral to the specialized center for NPT and investigation of asthma in workers with occupational rhinitis $[4-8 \bullet \bullet, 9 \bullet \bullet]$.

\section{Medico-legal aspects}

\section{Assessment of disability and compensation}

Because it is clear that patients with occupational rhinitis have higher risk of developing occupational asthma, subjects with a definite diagnosis of occupational rhinitis should be considered impaired for the occupation which caused this situation. But it is not possible to assess the degree of functional disability in occupational rhinitis. The reason for this is the absence of objective criteria or reference values. The evaluation of disability in occupational asthma is also problematic, however there is more experience in this field and severity of asthma is often used. The severity of rhinitis should also be regulated according to the grading systems [4].

Due to the differences in regulations and policies, compensation practices vary from country to country. On the other hand there are differences in the definition of occupational rhinitis and evaluation of level of disability. Different compensation systems among the European countries have been reported by the EAACI Task Force on Occupational Rhinitis [4]. The determination and grading of disability varied among European countries and there was not a consensus on the compensation 
methods according to this report. It is suggested that compensation systems should be directed to relocation of workers to unexposed jobs instead of financial compensation [49].

\title{
Compliance with Ethics Guidelines
}

\author{
Conflict of Interest \\ Dilșad Mungan declares no conflict of interest.
}

Human and Animal Rights and Informed Consent

This article does not contain any studies with human or animal subjects performed by any of the authors.

\section{References and Recommended Reading}

Papers of particular interest, published recently, have been highlighted as:

- Of importance

- Of major importance

1. Sublett JW, Bernstein DI. Occupational rhinitis. Curr Allergy Asthma Reports. 2010;10:99-104.

2. Gautrin D, Desrosiers M, Castano R. Occupational rhinitis. Curr Opin Allergy Clin Immunol. 2006;6:77-84.

3.• Moscato G, Pala G, Sastre J. Specific immunotherapy and biological treatments for occupational allergy. Current Opinion in Allergy and Clinical Immunology 2014 ( ebup ahead of print).

A comprehensive review on recent immunological treatment modalities in occupational allergy

4. Moscato G, Vandenplas O, Van Gerth WR, et al. EAACI Task Force on Occupational Rhinitis, Position Paper. Allergy. 2008;63:969-80.

5. Johansson SG, Hourihane JO, Bousquet J, et al. A revised nemenclature for allergy. An EAACI position statement from the EAACI nomenclature task force. Allergy. 2001;56:813-24.

6. Vandenplas O, Malo JL. Definitions and types of work related asthma: anosological approach. Eur Respir J. 2003;21:706-12.

7. Malo J, Vandenplas O. Definitions and classification of work-related asthma. Immunol Allergy Clin N Am. 2011;31:645-62.

8.• Hox V, Steelant B, Fokkens W, et al. Occupational upper airway disease: how work affects the nose. Allergy. 2014;69:282-91.

An excellent article dealing with every aspect of occupational rhinitis.

9.• Tarlo SM, Lemiere C. Occupational asthma. N Engl J Med. 2014;370(7):640-9.

A comprehensive rewiev on occupational asthma.
10. Megss WJ. RADS and RUDS - the toxic induction of asthma and rhinitis. J Toxicol Clin Toxicol. 1994;32:487-501.

11. Castano R, Theriault G. Defining and classifying occupational rhinitis. J Laryngol Otol. 2006;120:812-7.

12. Henneberger PK, Redlich CA, Callahan DB, et al. An official American Thoracic Society statement: workexacerbated asthma. Am J Respir Crit Care Med. 2011;184:368-78.

13. Vandenplas O. Asthma and rhinitis in the workplace. Curr Allergy Asthma Rep. 2010;10:373-80.

14. Siracusa A, Desrosiers M, Marabini A. Epidemiology of occupational rhinitis: prevalence, aetiology and determinants. Clin Exp Allergy. 2000;30:1519-34.

15. Bousquet J, Khaltaev N, Cruz AA, et al. Allergic Rhinitis and its impact on asthma (ARIA) 2008 update. Allergy. 2008;63 Suppl 86:8-160.

16. Leynaert B, Neukirch C, Kony S, et al. Association between asthma and rhinitis according to atopic sensitization in a population based study. J Allergy Clin Immunol. 2004;113:86-93.

17. Cullinan P, Cook A, Gordon S, et al. Allergen exposure, atopy and smoking as determinants of allergy to rats in a cohort of laboratory employees. Eur Respir J. 1999;13:1139-43.

18. Malo JL, Lemiere C, Desjardins A, et al. Prevalence and intensity of rhinoconjunctivitis in subjects with occupational asthma. Eur Respir J. 1997;10:1513-5.

19. Ameille J, Hamelin K, Andujar P, et al. Occupational asthma and occupational rhinitis: the united airways 
model revisited. Occup Environ Med.

2013;70(7):471-5.

20. Yılmaz İ, Erkekol FÖ, Seçil D, et al. Cat and dog sensitization in pet shop workers. Occup Med.

2013;63(8):563-7.

21. Heederik D, Venables KM, Malmberg P, et al. Exposureresponse relationships for work related sensitization in workers exposed tor at urinary allergens: results from a pooled study. J Allergy Clin Immunol. 1999;103:67884.

22. Musk AW, Venables KM, Crook B, et al. Respiratory symptoms, lung function, and sensitization to flour in a british bakery. Br J Ind Med. 1989;46:636-42.

23. Houba R, Heederik D, Doekes G, et al. Wheat sensitization and work related symptoms in the baking industry are preventable. An epidemilogic study. Am J Respir Crit Care Med. 1998;158:1499-503.

24. Cullinan P, Harris JM, Newman Taylor AJ, et al. An outbreak of astma in a modern detergent factory. Lancet. 2000;356:1899-900.

25. Demoly P, Bozonnat MC, Dacosta P, et al. The diagnosis of asthma using a self questionnaire in those suffering from allergic rhinitis: a pharmacoepidemiological surveyin everyday practice in France. Allergy. 2006;61:699-704.

26. Vandenplas O, Ghezzo H, Munoz X, et al. What are the questionnaire items most useful in identifying subjects in occupational asthma? Eur Respir J. 2005;26:105663.

27. Malm L, van Gerth Wijk R, Bachert C, et al. Guidelines for nasal provocations with aspects of nasal patency, airflow and airflow resistance. Rhinology. 2000;38:1-6.

28. Renstrom A, Malmberg P, Larsson K, et al. Prospective study of laboratory animal allergy: factors predisposing to sensitization and development of allergic symptoms. Allergy. 1994;49:548-52.

29. Litvyakova LI, Baranjuk JN. Nasal provocation testing: a review. Ann Allergy Asthma Immunol. 2001;86:355-64.

30. Airaksinen L, Tuomi T, Vanhanen M, Voutilainen R, Toskala E. Use of nasal provocation test in the diagnostics of occupational rhinitis. Rhinology.

2007;45:40-6.

31. Howarth PH, Persson CG, Meltzer EO, et al. Objective monitoring of nasal airway inflammation in rhinitis. J Allergy Clin Immunol. 2005;115(3pt2):S414-41.

32. Nathan RA, Eccles R, Howarth PH, et al. Objective monitoring of nasal patency and nasal physiology in rhinitis. J Allergy Clin Immunol. 2005;115(3pt2):44259.

33. Birdi K, Beach J. Management of sensitizer induced occupational asthma: avoidance or reduction of exposure? Curr Opin Allergy Clin Immunol. 2013;13:132-7.

An interesting rewiev including the comparisons between complete avoidance and reduction of exposure in occupational asthma.
34. De Groene GJ, Pal TM, Beach J et al. Workplace interventions for treatment of occupational asthma. Cochrane Database Syst Rev 2011: CD006308.

35. Vandenplas O, Dressel H, Wilken D, et al. Management of occupational asthma: cessation or reduction of exposure? A systematic review of available evidence. Eur Respir J. 2011;38:804-11.

36. Crivellaro M, Senna G, Marcer G, et al. Immunologic treatments for occupational allergy. Int J

Immunopathol Pharmacol. 2013;26(3):579-84.

37. Nettis E, Delle Donne P, Di Leo E, et al. Latex immunotherapy: state of the art. Ann Allergy Asthma Immunol. 2012;109:160-5.

38. Cirla AM, Lorenzini RA, Cirla PE. Specific immunotherapy and relocation in occupational allergic bakers. G Ital Med Lav Ergon. 2007;29:443-5.

39. Hansen I, Hormann K, Klimek L. Specific immunotherapy in inhalative allergy tor at epithelium. Laryngorhinootologie. 2004;83:512-5.

40. Heffler E, Guida G, Bruna E, et al. Occupational rhinitis in a cow breeder monosensitized to cow dander. Allergy. 2010;65:657.

41. Casale TB, Condemi J, La Force C, et al. Effects of omalizumab on symptoms of seasonal allergic rhinitis: a randomized controlled trial. JAMA. 2001;286:295667.

42. Vignola AM, Humpert M, Bousquet J, et al. Efficacy and tolerability of Anti IgE therapy with omalizumab in patients with concomitant allergic asthma and persistent allergic rhinitis: SOLAR. Allergy. 2004;59:709-17.

43. Leynadier F, Doudou O, Gaouar H, et al. Effect of omalizumab in healthcare workers with occupational latex allergy. J Allergy Clin Immunol. 2004;113:360-1.

44. Olivieri M, Biscardo CA, Turri S, et al. Omalizumab in severe baker's asthma. Allergy. 2008;63:790-1.

45. Lavaud F, Bonniaud P, Dalphin JC, et al. Usefulness of omalizumab in ten patients with severe occupational asthma. Allergy. 2013;68:813-5.

This study shows that treatment with Omalizumab in workers with severe occupational asthma is a promising approach as seven out of ten workers could remain in their job.

46. Sarlo K. Control of occupational asthma and allergy in the detergent industry. Ann Allergy Asthma Immunol. 2003;90 Suppl 2:32-4.

47. Gordon S, Preece R. Prevention of laboratory animal allergy. Occup Med. 2003;53:371-7.

48. Fishwick D, Harris Roberts J, Robinson E, et al. Impact of worker education on respiratory symptoms and sensitization in bakeries. Occup Med. 2011;61:321-7.

49. Nicholson PJ, Cullinan P, Taylor AJ, et al. Evidence based guidelines for the prevention, identification and management of occupational asthma. Occup Environ Med. 2005;62:290-9. 